\title{
Changes in endocrine profile and reproductive organs during puberty in the male marmoset monkey (Callithrix jacchus)
}

\author{
Ramesh K Chandolia, Craig Marc Luetjens, Joachim Wistuba, Ching-Hei Yeung, \\ Eberhard Nieschlag and Manuela Simoni \\ Institute for Reproductive Medicine of the University, Domagkstr 11, D-48129 Muenster, Germany \\ Correspondence should be addressed to E Nieschlag; Email: eberhard.nieschlag@ukmuenster.de
}

R K Chandolia who is now at the Department of Animal Reproduction, Gynaecology \& Obstetrics, Haryana Agricultural University, Hisar 125004, India.

\begin{abstract}
Data on pubertal maturation in male marmoset, a model for human reproduction, are scant and conflicting. We collected data on novel parameters to characterize puberty. Twenty-five marmoset monkeys were assigned to five age groups by weeks (wk): 21 (pre-pubertal), 43 (onset of puberty), 52 (fully pubertal), 70 (mature), and 116 (fully adult). Serum and intratesticular testosterone and pituitary bioactive chorionic gonadotropin (bioCG) were measured. Testicular development was assessed by ultrasonography, histology, and flow cytometry. Three consecutive blood samples revealed extreme fluctuations in testosterone concentrations, suggesting an erratic secretion. Age-related changes in serum testosterone and pituitary bioCG concentrations were observed. Intratesticular androgens (ITAs) showed high fluctuations within groups at all ages and were high in some animals by 21 wk. Unexpectedly, no correlation between pituitary bioCG and serum testosterone or ITAs was found, but these parameters significantly correlated with testicular weight and volume. These observations were consistent a dependence on the testis growth on bioCG. Unfortunately, the low serum levels of bioCG were not measurable in this study. At 43 wk, the animals reached puberty. At $52 \mathrm{wk}$ of age, animals attained maximum body and epididymal weights and qualitatively normal spermatogenesis, but testes continued growing, reaching a maximum of all parameters at $70 \mathrm{wk}$ of age, without further major changes at the age of $116 \mathrm{wk}$. It is concluded that (1) gonadal activation is evident at wk 21, (2) the male marmoset reaches the pubertal threshold around $43 \mathrm{wk}$ of age, attains qualitative parameters at $52 \mathrm{wk}$, matures further to sexual maturity at $70 \mathrm{wk}$, and (3) serum testosterone and ITAs are highly variable without any identifiable correlation with pituitary bioCG.
\end{abstract}

Reproduction (2006) 132 355-363

\section{Introduction}

The New World monkey Callithrix jacchus represents a non-human primate model, an alternative to Old World monkeys, to be used in reproductive physiology studies. As in human, male marmosets reproductive development leading to puberty also has three phases of endocrine events (1) neonatal activation of the pituitary-gonadal axis up to 16 weeks (wk) of age, (2) a quiescent phase up to $35 \mathrm{wk}$ of age (Lunn et al. 1994, 1997), and (3) reactivation of the pituitary-gonadal axis leading to onset of puberty, which was found to occur in our colony of marmosets between 40 and 52 wk (Wistuba et al. 2006). The onset of puberty was ascertained in intact controls by an increase in serum testosterone levels from values below $10 \mathrm{nmol} / \mathrm{l}$ to values above $80 \mathrm{nmol} / \mathrm{l}$ (Wistuba et al. 2006). However, in the marmoset, unlike in other species, the blockade of neonatal activation of the pituitary-gonadal axis has a minor effect on future proliferation of germ cells (Sharpe et al. 2003). In addition, the marmoset monkeys are different from other non-human primates as it does not express the $\beta$-subunit of luteinizing hormone $(\mathrm{LH})$, but the $\beta$-subunit of chorionic gonadotropin (CG) in the pituitary, which is the only gonadotropin with $\mathrm{LH}$ activity, is expressed in this species (Müller et al. 2004, Luetjens et al. 2005). The action of CG in the marmoset is mediated by a modified $\mathrm{LH}$ receptor isoform lacking exon 10 in its mRNA (Gromoll et al. 2003), which makes marmosets different from Old World monkeys. Recent observations from the studies on transplantation of testicular tissues (Wistuba et al. 2004, 2006) indicate that conditions needed for the initiation of spermatogenesis in this species are remarkably different from other species. In these studies, neither local testosterone nor 
supplemented human chorionic gonadotropin (hCG) could induce maturation of the immature testicular tissues of marmoset in nude mice host. Moreover, increased levels of gonadotropin after gonadectomy (Hodges 1978), but failure of gonadotrophin-releasing hormone $(\mathrm{GnRH})$ agonist to stimulate gonadotropin and testosterone concentrations (Lunn et al. 1990) further suggest the peculiar endocrine regulation of testicular function in this species as demonstrated previously by us (Gromoll et al. 2003, Müller et al. 2004).

On the other hand, this animal is becoming popular as a non-human primate model because of its small size and easy handling. This species has also been claimed to have spermatogenic patterns closely resembling human spermatogenesis (Millar et al. 2000, Wistuba et al. 2003) as the spermatogenic organization of the testicular epithelium is similar to the human, providing another argument for using this species as model for human reproduction.

Since review of the literature on marmosets presented divergent data on organ development and endocrinology ( $\mathrm{Li}$ et al. 2005), the purpose of the present study was to observe changes in the pituitary-gonadal axis and reproductive parameters in the developing marmoset, to assess the development of reproductive organs and correlate them to cellular components of the testis. The emphasis was to provide a complete characterization of puberty, which is the sequence of key events in sexual maturation. We chose five different marmoset age groups, that is, the first clearly prior to puberty in the quiescent phase, the second at the beginning of puberty onset, the third at the very end of puberty onset, the fourth in late adolescence and last group of adult animals, which had fathered offspring. Our observations of pubertal events in this animal model might have decisive impact for future experimental approaches. In this study, testicular development was assessed through ultrasonography, flow cytometry, and histology. Pituitary bioactive chorionic gonadotropin (bioCG), measured for the first time, was correlated with serum testosterone and intratesticular androgens (ITAs), testicular weight and volume, and other parameters.

\section{Materials and Methods}

\section{Animals and study design}

In a cross-sectional study design, 25 male marmoset monkeys $(C$. jacchus) of five age groups were selected $(n=5)$. The age (mean \pm S.E.M.) groups were $21.5 \pm 0.1$ wk (before puberty), $43.3 \pm 0.7 \mathrm{wk}$ (at the onset of puberty), $52.8 \pm 0.3 \mathrm{wk}$ (full puberty), $70.1 \pm 0.4 \mathrm{wk}$ (mature), and 116.8 $\pm 20 \mathrm{wk}$ (full adult). These animals were taken from the marmoset breeding colony of our Institute, which has been a self-sustained colony of about 180 animals since 9 years. The groups were referred as $21,43,52,70$, and 116 wk in 'Results and Discussion' section. The experimental work was performed in accordance with the German Federal Law on the Care and Use of Laboratory Animals (License G67/2001).

\section{Ultrasonography of testes}

The ultrasonographic scanning of testes (ultrasound equipment: Hewlett Packard and a transducer of 12.0 $\mathrm{MHz}$ ) was performed 1 day before sacrificing the animals. The in situ dimensions of the testes were measured using electronic callipers in the ultrasound equipment. The images were stored in an optic disc and subjected to computerized analysis for gray-scale values with the help of a computer program (Metamorph version 6.2, Universal Imaging Corp., Downingtown, PA, USA). The ultrasonic measurements of length and width of testes were used to calculate testicular volume on the basis of a formula used previously (Zitzmann et al. 2003).

\section{Blood samples}

Three blood samples were taken from the femoral vein of each animal at 2-h intervals. The first two samples were collected without sedation, while the third sample was collected immediately after ketamine sedation, just prior to organ collection. The samples were collected between 0830 and 1230 . The serum was separated and stored at $-20{ }^{\circ} \mathrm{C}$ till analysis.

\section{Hormone assays}

The bioCG was measured in pituitary homogenates as described previously (Müller et al. 2004). In brief, bioCG levels were measured by an in vitro bioassay based on murine Leydig cells, according to a previously established method for bioactive LH measurement (Wickings et al. 1979, Luetjens et al. 2006). Sensitivity of the assay for an initial plasma dilution of 1:10 was $1.76 \mathrm{IU} / \mathrm{l}$ using the human standard (WHO 78/549). Marmoset pituitary homogenates and serum samples gave parallel results. The intra- and inter-assay coefficients of variation (CV) were 11.5 and $13 \%$ respectively. The assay sensitivity for bioCG was $0.06 \mathrm{IU} / \mathrm{l}$ in terms of WHO standard 78/549. Attempts were made to measure bioCG in serum samples, but the levels were below the assay's sensitivity except in two animals (data not presented). In assay validation experiments, we could exclude that serum testosterone interferes with the bioassay (data not shown). Serum testosterone and ITA were measured by the in-house RIA method (Chandolia et al. 1991). Since the antiserum used in the RIA cross-reacts $>95 \%$ with dihydrotestosterone (DHT), both testosterone and DHT are measured with this assay. Therefore, in the case of the testis, which contains very high levels of DHT, the measurement is referred to as ITA. The relatively low levels of DHT in serum, however, can be disregarded so 
that we express the serum values as testosterone (nmol/l). The intra- and interassay CV values were 6.5 and $12.9 \%$ respectively.

\section{Tissue collection and processing}

Each animal was anesthetized with ketamine, weighed, and sacrificed by exsanguination prior to start of organ collection, which took place between 1230 and 1400 in each group. The weights of testes, epididymides, and seminal vesicles were recorded immediately after removal. One of the two testes, epididymis, and seminal vesicle from each animal were fixed in Bouin's solution, while the other and the pituitary were snap frozen in liquid nitrogen and stored at $-80^{\circ} \mathrm{C}$. Paraffin sections of testicular and epididymal tissues were prepared for histology, while frozen parts were used for intratesticular testosterone and flow cytometric cellular quantification.

\section{Flow cytometry}

Flow cytometry was performed as described by Weinbauer et al. (2001), with slight modifications. In brief, parts of frozen testicular tissue were dissected at minus $-80{ }^{\circ} \mathrm{C}$ and transferred into the homogenization buffer to thaw at room temperature. About $20 \mathrm{mg}$ testicular tissue was minced and homogenized for $2 \mathrm{~s}$ followed by centrifugation at $40 \mathrm{~g}$ for $1 \mathrm{~min}$. The supernatant was incubated for $25 \mathrm{~min}$ with propidium iodide $(25 \mu \mathrm{g} / \mathrm{ml})$, RNase $(40 \mu \mathrm{g} / \mathrm{ml})$, and $0.3 \%$ nonidet P40 in PBS. The number of elongated haploid cells (HC), round spermatids (1C), spermatogonial and somatic cells (2C), cells in S-phase of the cycle and tetraploid cells comprising mainly primary spermatocytes and G-2 spermatogonia cells $(4 \mathrm{C})$ were quantified and were expressed as percentages.

\section{Histology}

The paraffin sections ( $3 \mu \mathrm{m}$ thick) were used to evaluate the maturation of the testis. Advanced cell types were counted in 400 tubules. In the testes of the prepubertal animals, in which such numbers of tubules were not present, the number was counted in multiple sections of the testis. The diameter of the seminiferous tubules and lumen and epithelial height were measured in 50 tubules in each group using a computerized program (Axioskop and Axiovision, Zeiss, Oberkochen, Germany). As there was no clearly identifiable lumen in the 21-wk-old group, the epithelial height was not presented in this group. In the second group ( $43.3 \pm 0.7 \mathrm{wk})$, there was no lumen in some tubules. The mean tubule diameters given for this group were combined values, while lumen diameters and epithelial heights were from tubules showing lumen.

\section{Statistical analysis}

For statistical analysis of data, repeated measures of ANOVA, multiple comparison of means (Tukey's test) and ANOVA on Ranks (Kruskal-Wallis one-way ANOVA) were processed by a computerized program (SPSS, Inc., version 12.0, Chicago, IL, USA). For single comparison tests, $P<0.05$ was considered as statistically significant. Correlations were analyzed by Spearman ranks. After Bonferroni's corrections for multiple comparisons, in Table 1, correlations were considered statistically significant when $P<0.007$. The weight of both testes showed a similar pattern of growth, therefore, the data of left and right testis were combined. All data were expressed as mean \pm s.E.M. The gray-scale values derived from computer analysis were displayed on the screen as value \pm s.D. of the entire ultrasonic image. The results presented here included mean of all the gray scale values and their S.D.s. Values were considered significantly different if $P<0.05$.

\section{Results}

Body weight increased significantly from wk 21 (184 $13 \mathrm{~g})$ to $43(293 \pm 20 \mathrm{~g})$ with a maximum at $52 \mathrm{wk}$ $(356 \pm 12 \mathrm{~g})$ of age and remained in this range (70 wk,

Table 1 Spearman rank order correlations among endocrine and reproductive parameters in marmoset monkeys $(n=25)$ and after Bonferroni's corrections $P<0.007$ was considered statistically significant.

\begin{tabular}{|c|c|c|c|c|c|c|c|}
\hline Variables & Body weight & Testis weight & Testis volume & $\begin{array}{l}\text { Epididymis } \\
\text { weight }\end{array}$ & $\begin{array}{l}\text { Mean serum } \\
\text { testosterone }\end{array}$ & $\begin{array}{c}\text { Intratesticular } \\
\text { androgens (ITAs) }\end{array}$ & $\begin{array}{l}\text { Pituitary bioactive } \\
\text { chorionic gonado- } \\
\text { tropin (bioCG) }\end{array}$ \\
\hline Age & $0.43(P=0.034)$ & $0.85(P=0.000)$ & $0.83(P=0.000)$ & $0.34(P=0.091)$ & $0.48(P=0.016)$ & $-0.09(P=0.641)$ & $0.81(P=0.000)$ \\
\hline Body weight & & $0.59(P=0.002)$ & $0.48(P=0.015)$ & $0.69(P=0.000)$ & $0.35(P=0.082)$ & $0.06(P=0.790)$ & $0.21(P=0.299)$ \\
\hline Testis weight & & & $0.80(P=0.000)$ & $0.49(P=0.013)$ & $0.57(P=0.003)$ & $-0.08(P=0.687)$ & $0.66(P=0.000)$ \\
\hline Testis volume & & & & $0.41(P=0.040)$ & $0.43(P=0.032)$ & $-0.03(P=0.873)$ & $0.78(P=0.000)$ \\
\hline Epididymis weight & & & & & $0.35(P=0.089)$ & $-0.01(P=0.972)$ & $0.25(P=0.228)$ \\
\hline $\begin{array}{l}\text { Mean serum } \\
\text { testosterone }\end{array}$ & & & & & & $0.33(P=0.107)$ & $0.31(P=0.136)$ \\
\hline $\begin{array}{l}\text { Intra-testicular } \\
\text { androgens }\end{array}$ & & & & & & & $-0.14(P=0.493)$ \\
\hline
\end{tabular}


$305 \pm 26 \mathrm{~g}$ and $116 \mathrm{wk}, 323 \pm 29 \mathrm{~g}$ ). The combined weight of testes, ratio of testes and body weight, and testicular volume were shown in Fig. 1. The testes weight increased significantly from 21 - to 43 -wk group, and a gradual increase was observed afterwards. The values at 70 and $116 \mathrm{wk}$ were significantly different from the other groups. A similar pattern was shown for the ratio of testes to body weight. Testicular volume showed a gradual increase up to $70 \mathrm{wk}$, when it was significantly higher compared to all previous ages. The volume at $116 \mathrm{wk}$ was in the range of 52 and $70 \mathrm{wk}$, but higher than other groups. The ratio between vertical and horizontal growth of testis was almost constant in all ages, i.e., $1.5 \pm 0.1$. There was an increase in mean echogenicity from $21 \mathrm{wk}$
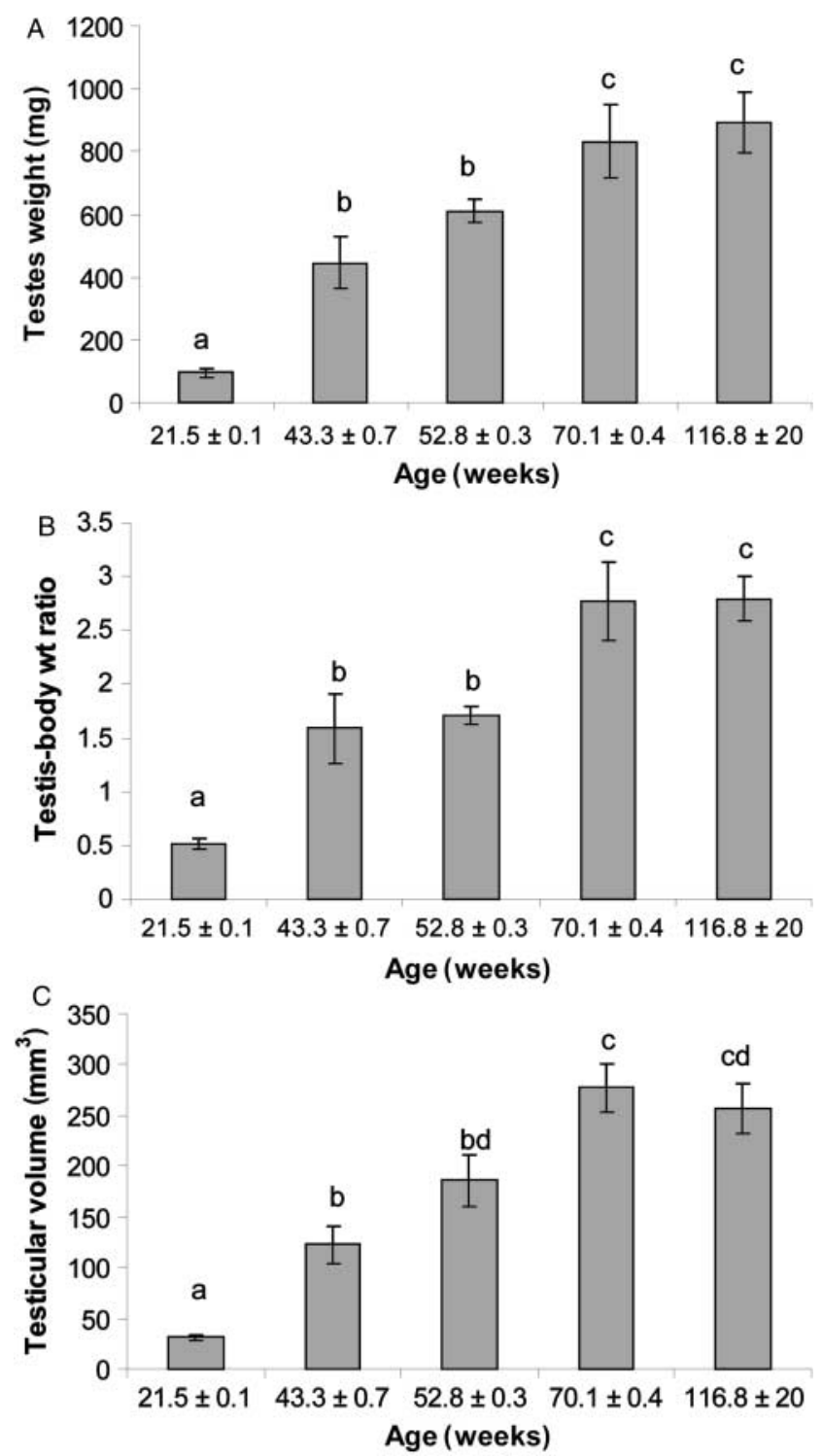

Figure 1 Combined testes weight (A), ratio of testis and body weight (B), and testicular volume $(C)$ in marmoset monkeys of different age groups $(n=5)$. Values with different superscripts differ significantly among age groups at $P<0.05$.
$(101.6 \pm 16.6)$ to $43 \mathrm{wk}(119.7 \pm 17.5)$ and later it fluctuated marginally (52 wk, $115.0 \pm 17.9 ; 70 \mathrm{wk}$, $110.7 \pm 19$; and $116 \mathrm{wk}, 81.34 \pm 20.36$ ).

The weight of the epididymis (Fig. 2A) increased from wk 21 to 43, was highest at wk 52 and then fluctuated. The ratio of epididymis and body weight (Fig. 2B) was lowest at wk 21, while it reached a maximum at $43 \mathrm{wks}$ of age. Later it fluctuated, but within the range of wk 43. The ratio of epididymis and testis weight was highest at wk 21 and gradually decreased to significantly lower values at 70 and $116 \mathrm{wk}$ of age $(P<0.05)$.

The diameter of the seminiferous tubules (Fig. 3) was smallest at wk 21 and increased linearly and significantly $(P<0.05)$ reaching a maximum at $70 \mathrm{wk}$ of age. In the
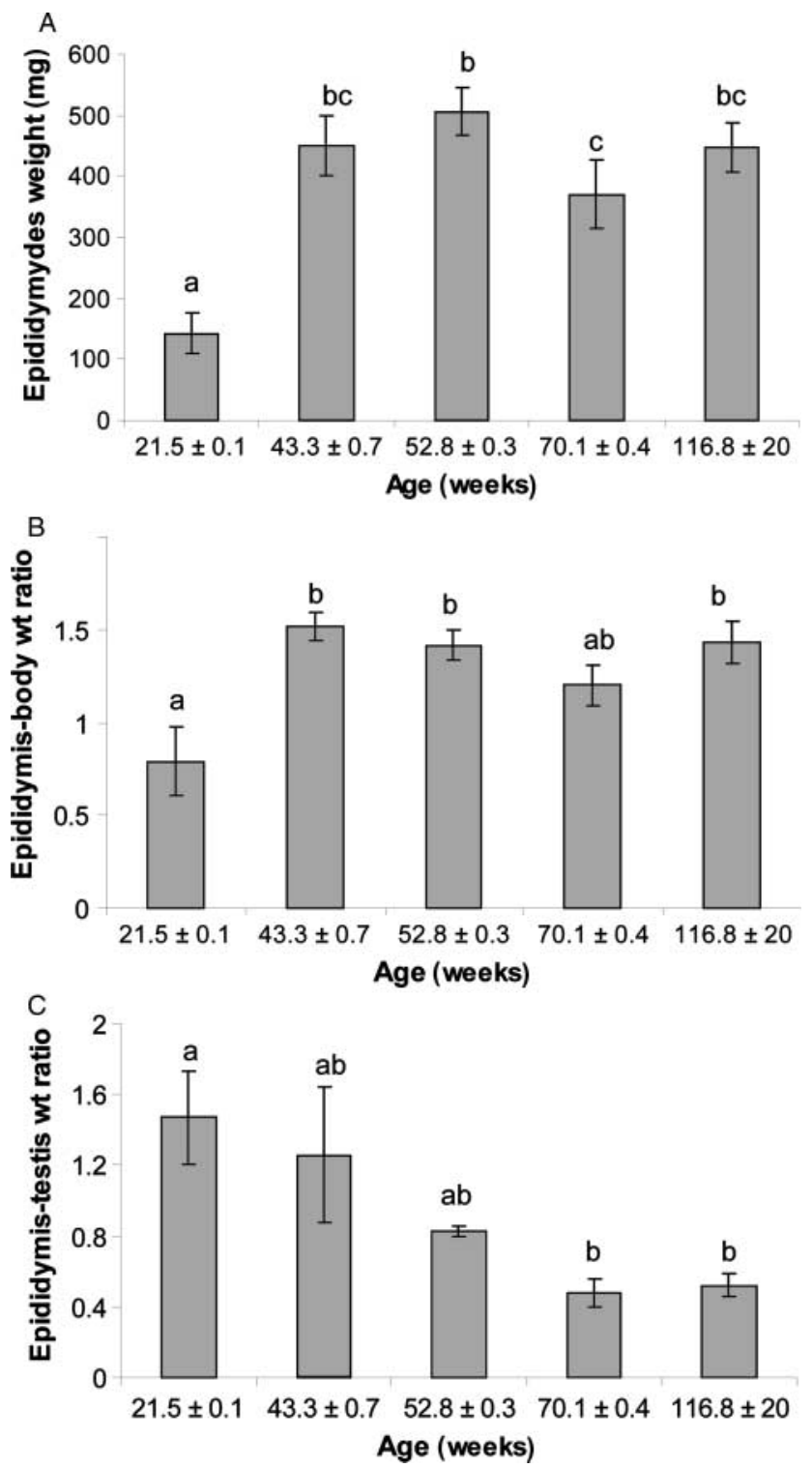

Figure 2 Epididymal weight (A), ratio of epididymis and body weight (B), and ratio of epididymis and testis weight $(C)$ in marmosets of different age groups $(n=5)$. Different superscripts indicate differences among age groups at $P<0.05$. 


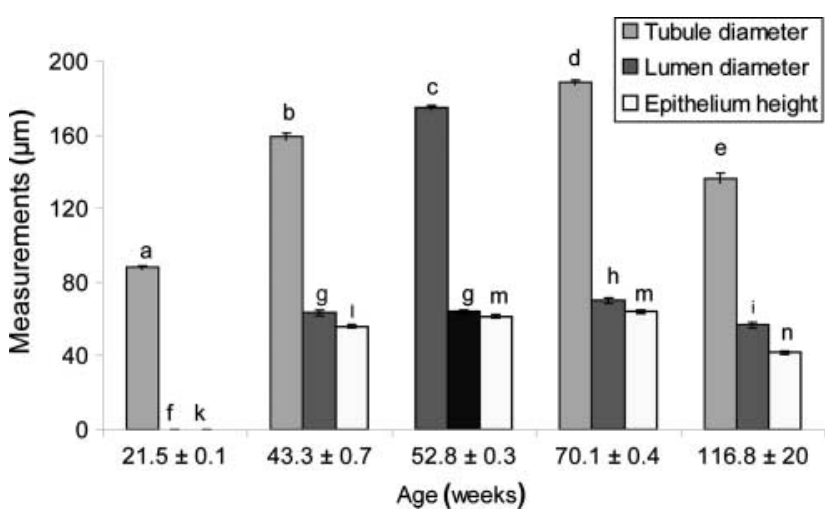

Figure 3 Seminiferous tubule and lumen diameters and epithelial height $(\mu \mathrm{m})$ in marmoset monkeys of different age groups. Data are the mean \pm S.E.M. of $5 \times 50$ tubules in each group. Different superscripts, within group, indicate significant differences $(P<0.05)$. The superscripts from ' $a$ ' to ' $\mathrm{e}$ ' show comparison among tubule diameters, from ' $\mathrm{f}$ ' to ' $i$ ' among lumen diameters and from ' $k$ ' to ' $n$ ' among epithelium heights.

older group of marmosets, the diameter of seminiferous tubules declined significantly $(P<0.05)$. The lumen was not present at $21 \mathrm{wk}$, therefore, the thickness of epithelium was not measured. The lumen did not change from wk 43 to 52, increased significantly at wk 70 and then declined $(P<0.05)$. Epithelial height increased significantly from wk 43 to 52, remained in this range at wk 70, and later declined $(P<0.05)$.

The testicular histology of 21-wk-old animals (Fig. 4) showed that the tubules comprised, besides the Sertoli cells, only gonocytes not yet attached to the peritubular walls and early spermatogonia adjacent to tubule walls. No further development of germ cells was observed,

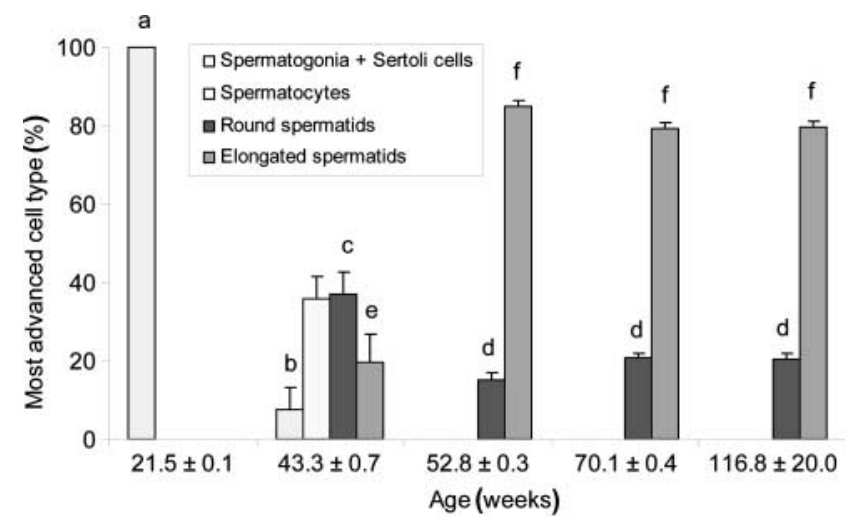

Figure 4 Most advanced cell types present at different age groups of marmoset monkey testis. The cells are abbreviated as elongated spermatids (elongated spermatids), round spermatids (round spermatids), spermatocytes (spermatocytes), and spermatogonia + sertoli cells (spermatogonia + sertoli cells). The data are the mean of 400 tubules counted ( $n=5$ in each age group). When only few tubules were present at young ages, multiple sections of tubules were counted. Different superscripts present significant different values $(P<0.05)$, between age groups, but within tubules having same type of advance cells (superscripts ' $a$ ' and ' $b$ ' for spermatogonia + Sertoli cells only, ' $c$ ' and ' $d$ ' for round spermatids, and ' $\mathrm{e}$ ' and ' $\mathrm{f}$ ' for elongated spermatids). whereas many germ cells at $43 \mathrm{wk}$ of age had undergone meiotic divisions and some went through the process of spermiation leading to elongated spermatids. In the other age groups of 52, 70, and $116 \mathrm{wk}$, all tubules contained postmeiotic round and elongated spermatids as the most advanced cells.

The histology sections (Fig. 5A) at $21 \mathrm{wk}$ age revealed three kinds of differentiating spermatogonia (gonocytes), that is, one cell type was present towards the center without any contact to basal lamina. Other large cells had an orientation to and partial contact with the basal lamina, while the third cell type was positioned between the Sertoli cells. In some tubules, there were large spaces around the center (data not shown). At $43 \mathrm{wk}$ of age, various stages of cellular maturation were present (Fig. 5B). Some tubules resembled those of wk 21, while others showed development up to spermatocytes
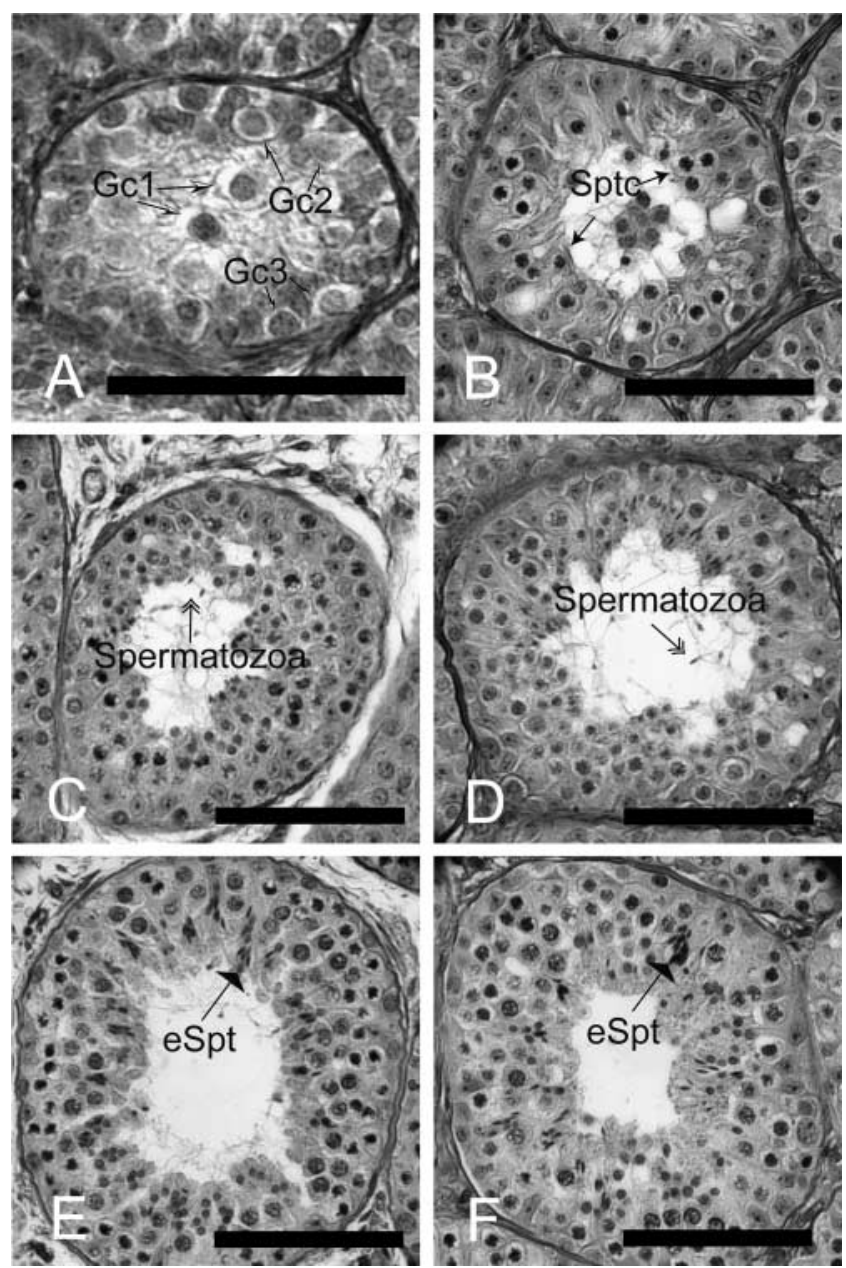

Figure 5 Histology of testicular sections in marmoset monkeys in different age groups. At 21 weeks (wk) (A) three types of differentiating spermatogonia (Gc1, unattached; Gc2, partially attached; Gc3, fully attached) were seen. In the second group of $43 \pm 2 \mathrm{wk}$, development up to spermatocytes with lumen (B), and elongated spermatids or

spermatozoa indicated by the arrow (C) were seen. At later stages (52, 70, and $116 \mathrm{wk}$ ) full spermatogenesis (D)-(F) was seen. 
with the appearance of lumen. Some tubules showed development into the elongated spermatids or spermatozoa (Fig. 5C). This group was very heterogeneous and all cell types were present, percentages of spermatocytes, elongated and round spermatids being almost equal (Fig. 4). In the three older groups (52, 70, and 116 $w k)$, the tubules showed the presence of round and elongated spermatids as the most prominent cell types (Fig. 5D-F). At this age, Sertoli cells were also found to be associated with a group of 5-6 elongated spermatids. The tubules at wk 70 and 116 showed full adult spermatogenesis (Fig. 5E and F).

The histological sections of the epididymis showed absence of sperm at wk 21 and some at 43. At wk 52, high amounts of sperm were present in the epididymis, which apparently increased in abundance at wk 70 and older (data not shown).

The flow cytometric sorting of testicular cells (Fig. 6) showed that HC (highly condensed) and 1C (haploid) cells were absent at $21 \mathrm{wk}$. The majority of cells at this stage were $2 \mathrm{C}$, while a few $4 \mathrm{C}$ were also present. The HC cells appeared in the 43-wk age group and increased significantly at 70 and $116 \mathrm{wk}$ in comparison to 43 and $52 \mathrm{wk}(P<0.05)$. The percentage of $1 \mathrm{C}$ cells increased significantly from 43 to $52 \mathrm{wk}$ of age $(P<0.05)$ and plateaued at that level. The proportion of $2 \mathrm{C}$ cells reached a maximum at $21 \mathrm{wk}$ of age and declined significantly in all other groups $(P<0.05)$. The $4 \mathrm{C}$ cells were low at $21 \mathrm{wk}$ and increased and reached significantly higher number at $52 \mathrm{wk}$ of age $(P<0.05)$.

The serum testosterone concentration fluctuated considerably in the three samples with large inter- and

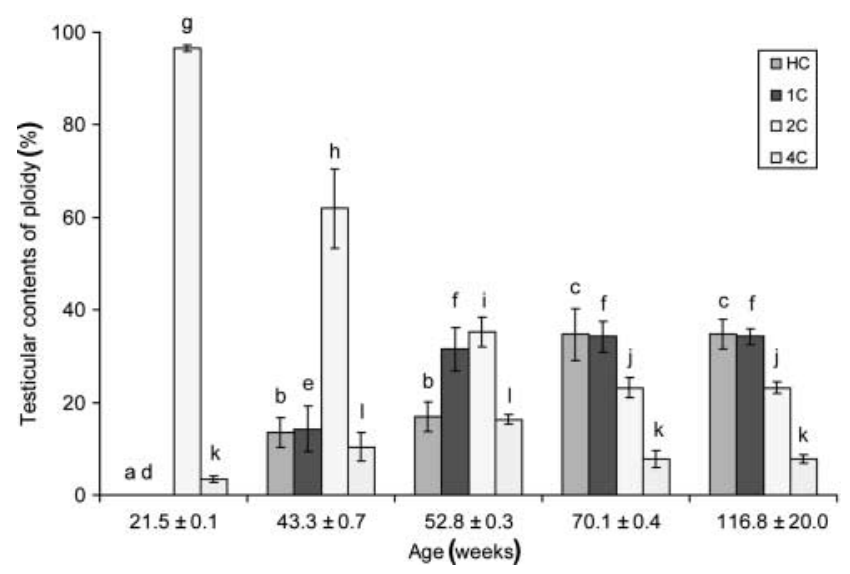

Figure 6 Flow cytometric quantitation of testicular cells (testicular contents of ploidy) in marmoset monkeys. Values of each cell type are presented as percent of all the four cell types shown in the graph. HC cells are cells with compact DNA and represent elongated spermatids. 1C cells represent haploid round spermatids. Spermatogonia and somatic cells are mailnly $2 \mathrm{C}$ cells. $4 \mathrm{C}$ cells are tetraploid cells comprising mainly primary spermatocytes and G2-spermatogonia cells. Values with different superscripts differ significantly $(P<0.05)$ between ages, but within a category (superscripts ' $a$ ' $-{ }^{-} \mathrm{c}$ ' for $\mathrm{HC}$ cells, ' $d{ }^{\prime}-{ }^{\prime}{ }^{\prime}$ for $1 C,{ }^{\prime} g^{\prime}-{ }^{\prime} j$ ' for $2 C$, and ' $k$ ' and ' $\mathrm{l}$ ' for $4 \mathrm{C}$ ). intra-individual variations at all ages (Fig. 7). At 21 wk, the values varied between 3 and $20 \mathrm{nmol} / \mathrm{l}$. At $43 \mathrm{wk}$, testosterone fluctuated between 4 and $40 \mathrm{nmol} / \mathrm{l}$. At 52 wk of age, the values fluctuated to higher levels, i.e., between 3 and $70 \mathrm{nmol} / \mathrm{l}$. The 70 -wk age group showed maximum peak values, swinging between 3 and $180 \mathrm{nmol} / \mathrm{l}$ and at $116 \mathrm{wk}$, the values were between 4 and $120 \mathrm{nmol} / \mathrm{l}$.

The bioCG in pituitary homogenates (Fig. 8A), showed lower concentrations at 21 and $43 \mathrm{wk}$, while it increased at wk $52(P>0.05)$, reaching higher levels at 70 and 116 wk $(P>0.05)$. The levels at wk 52 were between 1000 and $4000 \mathrm{IU} / \mathrm{l}$, at $\mathrm{wk} 70$, the values were between 4000 and $12000 \mathrm{IU} / \mathrm{l}$ and at $116 \mathrm{wk}$ and later, the values fluctuated between 4000 and $22000 \mathrm{IU} / \mathrm{l}$. The ITA levels (Fig. 8B) showed large inter-individual fluctuations at wk 21. These fluctuations decreased at wk 43 , stabilized at wk 52 and 70, and were more evident at wk 116.

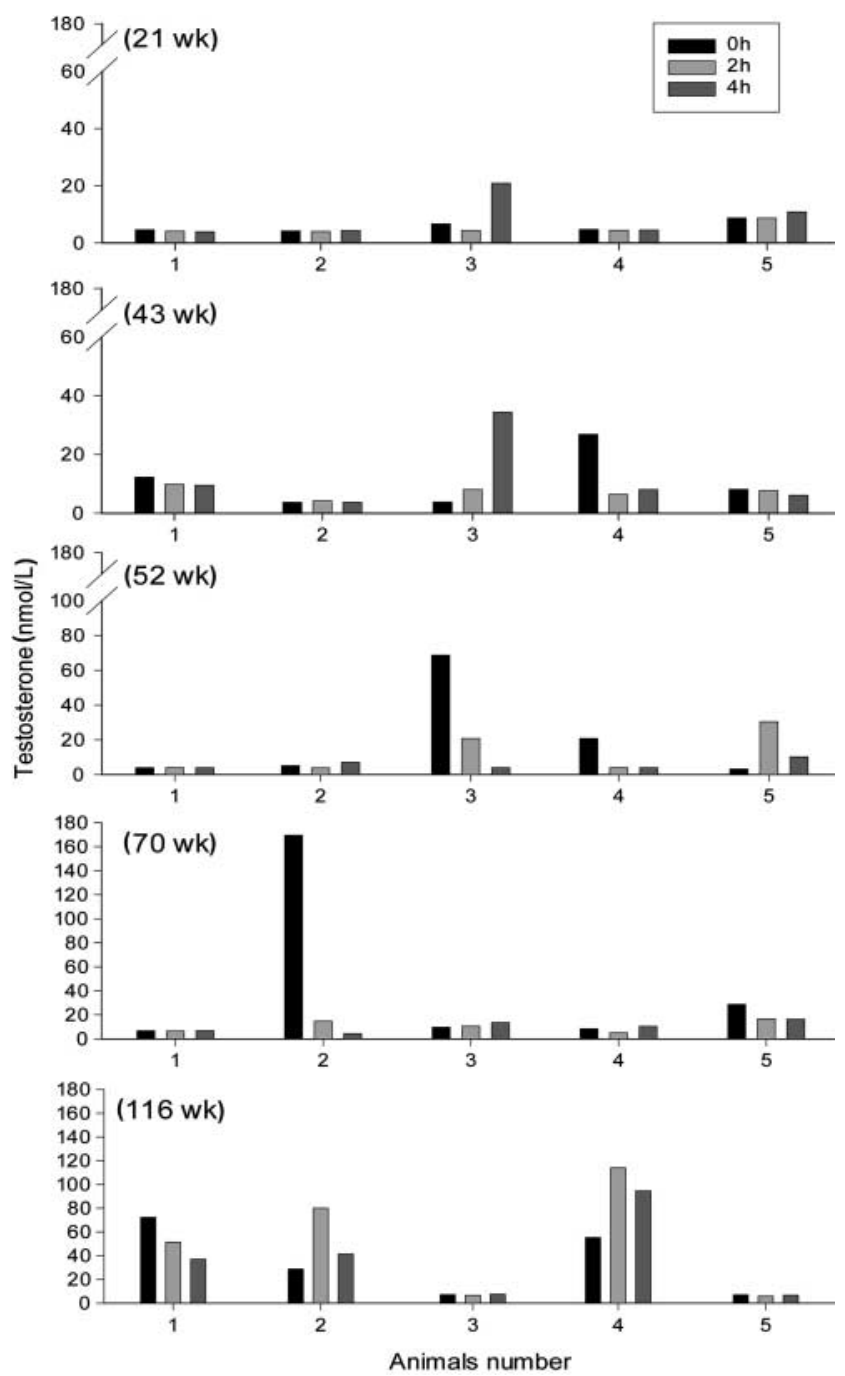

Figure 7 Serum testosterone concentrations in multiple samples taken at 2-h intervals from individual marmoset monkeys on the day of sacrifice. All the five animals of each age group (21, 43, 52, 70, and 116 wk) were analyzed. 

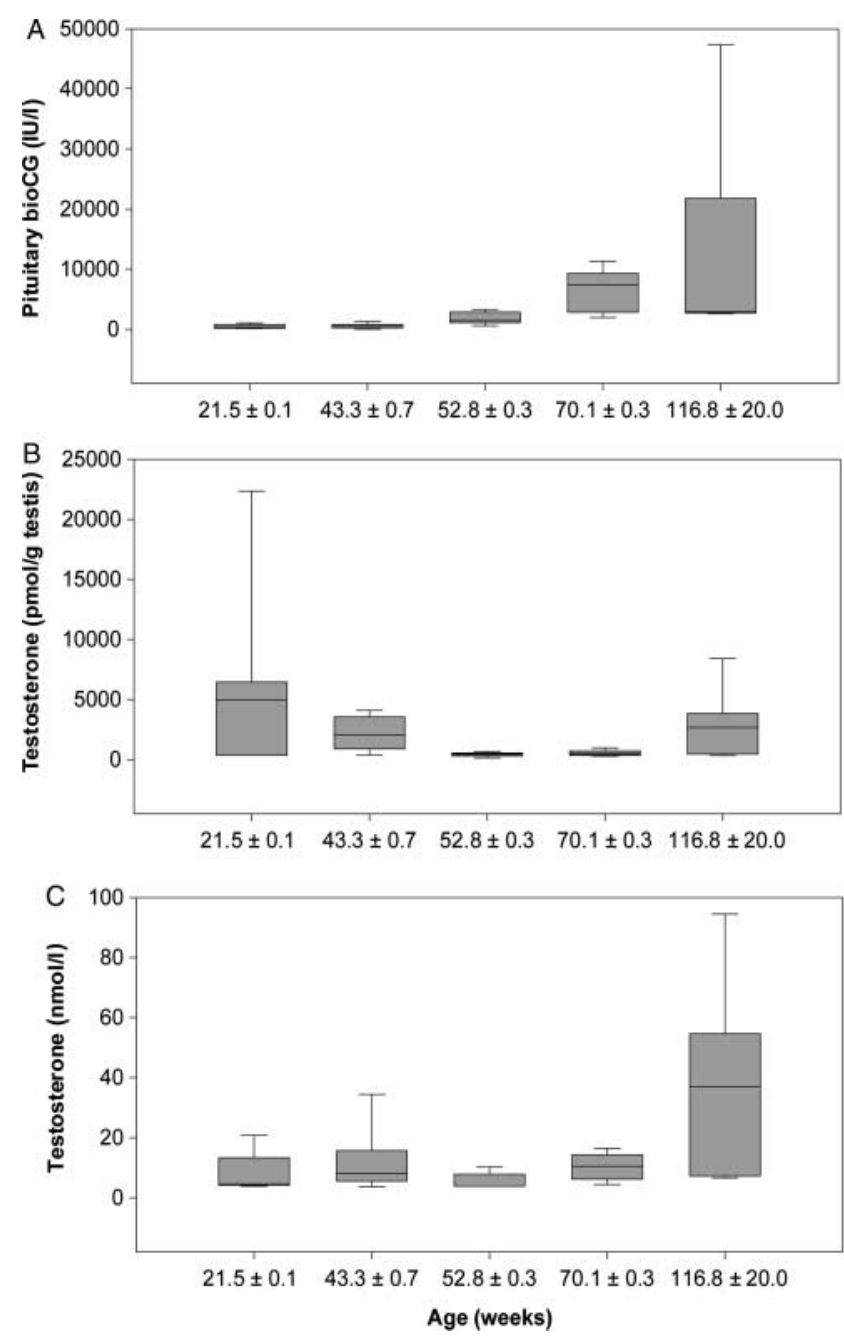

Figure 8 Box and whisker plots showing the upper and lower quartiles as well as the statistical median of pituitary bioactive chorionic gonadotropin (bioCG) (A), intratesticular androgens (ITAs) (B), and serum testosterone in sample taken during sacrifice (C), in different age groups of marmoset monkeys ( $n=5 /$ group).

Serum testosterone measured in the samples taken just prior to organ removal (Fig. 8C) also showed less interindividual fluctuations at wk 52 and 70 with higher fluctuations at other ages.

Table 1 shows correlation among endocrine and reproductive parameters. The age was positively correlated to testis weight and volume and pituitary bioCG. Body weight showed positive correlation with testis and epididymal weights, but showed no correlation with testis volume, serum testosterone, ITAs, and pituitary bioCG. Testis weight was positively correlated with both serum testosterone and pituitary bioCG, while testis volume was correlated with bioCG only. There was no correlation between pituitary bioCG and either mean serum testosterone or testosterone in the sample taken, just prior to organ removal $(P=0.20$, not shown in Table 1). ITAs did not show significant correlation with any of the parameters shown in Table 1 . In a single correlation of ITA levels to serum testosterone in the sample taken just prior to organ removal showed $P=0.046$, but in the multiple comparison no significant correlation was found ( $P=0.107$, Table 1$)$.

\section{Discussion}

In the marmoset monkey, a neonatal activation of pituitary-gonadal axis occurs (Lunn et al. 1994) up to wk 15 or 16 (Abbott \& Hearn 1978). The quiescent period was reported to continue until the age of $35 \mathrm{wk}$ with non-detectable testosterone concentrations (Lunn et al. 1997, Kelnar et al. 2002). According to these observations, our first age group of $21 \mathrm{wk}$ represented the age at which the activation of hypothalamus-pituitarygonadal axis was not expected. Our study brought out two important observations at this age. First, the serum testosterone levels were measurable showing fluctuations in individual monkeys within the period of $6 \mathrm{~h}$. This could be due to the multiple sampling procedures. Secondly, the ITA concentrations were high at this age, with very high inter-individual variations. The moderate levels of ITA in one of the $21 \mathrm{wk}$ of age animals at one time point might be caused by the appearance of adult type Leydig cells at this age (Rune et al. 1991). In all other groups, fluctuation of serum testosterone within the period of $6 \mathrm{~h}$ demonstrates a rather erratic secretion of this hormone in this species. In the single comparison of intratesticular with serum testosterone, taken just prior to the removal of organs, the moderate positive correlation at least rules out the assays themselves as a source of fluctuation. Extreme individual variations in testosterone concentrations have been reported previously (Dixson 1986, Lunn et al. 1994). Marmosets have been shown to have sex hormone binding globulin. Although Hodges et al. (1983) reported low free testosterone levels (approximately 1.7-4.5\%) in marmoset serum, Lunn et al. (1997) more recently demonstrated higher levels of biologically active testosterone. Pugeat et al. (1984) reported that plasma testosterone-estradiol binding protein in New World monkeys (including marmosets) has a low affinity despite high binding capacity for testosterone, resulting in high levels of unbound plasma testosterone in New World monkeys (20-40 ng/dl), as compared to those in Old World monkeys $(3-9 \mathrm{ng} / \mathrm{dl})$ or humans $(10 \mathrm{ng} / \mathrm{dl})$. The difference in binding characteristics may explain the pronounced testosterone fluctuations in marmosets.

The observed higher levels of bioCG and serum testosterone at $70 \mathrm{wk}$ and older in this study might be indicative of maturity of the pituitary-gonadal axis in marmoset (Lunn et al. 1994, Kelnar et al. 2002). Although stimulation of testosterone production has been shown after external administration of hCG (Kholkute et al. 1983), the current study could not establish a significant correlation of pituitary bioCG with either serum or testicular testosterone, suggesting that 
ITA production might be at least, in part, independent of pituitary secretion especially in the youngest group. Although Lunn et al. (1994) were able to correlate serum gonadotropin with serum testosterone, two other studies did not find this direct correlation in marmosets (Hodges \& Hearn 1977, Sharpe et al. 2003). These contradicting observations support the interpretation that blockade of pituitary-gonadal axis at early age must not successfully influence testicular parameters such as testosterone increase at puberty. Since, serum bioCG was not detected in these marmosets, the fluctuating testosterone values may also be due to a short pulsatile CG pituitary secretion. This may not be reflected due to serum sample frequency so that only a study in which the secretion is blocked would finally elicit a possible pituitary-serum correlation CG levels. However, testis weight and volume were correlated with CG suggesting that testicular maturation is positively correlated with increased CG production, but instantaneous ITA production and secretion seems to partly 'escape' pituitary control. The role of follicle-stimulating hormone in testicular maturation remains to be established as an assay method is not yet available.

Testicular volumes obtained through ultrasonography were lower than manual measurements (Abbott \& Hearn 1978), but were significantly correlated to testicular weight, indicating a linear relationship between them, which has been suggested previously (Jackson \& Edmunds 1984). Ultrasonography proved its usefulness in prediction of puberty and testicular development, particularly through gray-scale assessment of testis in this species.

Small testicular volume and absence of lumen in the seminiferous tubules at $21 \mathrm{wk}$ of age indicated immaturity of testis. The different location of immature cells observed at this age might be a sign of movement of cells towards the basal lamina (Sharpe et al. 2003). As in other species, this cellular process (McGuinness \& Orth 1992) might be critical for gonocyte survival and establishment of spermatogonial reserve in adulthood (de Souza et al. 1988). Degeneration and decrease in number of germ cells have been reported in the immature testis (Sharpe et al. 2000), which might explain the large spaces observed in the present study in the seminiferous tubules at wk 21.

Onset of puberty in marmosets occurs at a mean age of $43.3( \pm 0.7) \mathrm{wk}$. This was confirmed by the appearance of lumen in the tubule and the presence of all advanced cell types including spermatozoa in the testis at this age. This was also supported by the presence of spermatozoa in the epididymis and by flow cytometric data. Previously, the occurrence of puberty has been suggested at later ages (Lunn et al. 1994, Kelnar et al. 2002), however, individual variations among animals has also been reported (Jackson \& Edmunds 1984).

Observations from the age of wk $52.8( \pm 0.3)$ indicated full attainment of many reproductive parameters. Adult type body, epididymal and testicular weights, establishment of the adult pattern of spermatogenesis, and the abundant presence of spermatozoa in the epididymis were signs of qualitative attainment of spermatogenesis. This could be attributed to the development of adult morphology of testicular cells at this age (Sharpe et al. 2003).

Achievement of all the reproductive and endocrine parameters to their maximum at wk $70.1( \pm 0.4)$ indicated that the male marmoset had reached its full sexual maturity at this age. Between the age groups of wk 52 and 70, there were quantitative increase in $\mathrm{HC}$ cells and increases in epithelium thickness, lumen and tubule diameters. These changes were also reflected by an increase in testicular weight and volume during this period. These data confirm that maturity in marmosets although variable, occurs between 70 and $80 \mathrm{wk}$ of age (Jackson \& Edmunds 1984). Inclusion of the last age group 116.8 ( \pm 20 ) wk proved very useful in comparing changes from $70 \mathrm{wk}$ onwards. In this group, all parameters were in the range of $70 \mathrm{wk}$, indicating that the male marmoset monkey had already achieved full plateau of reproductive parameters at wk 70 and there were no major quantitative or qualitative changes later on.

It is concluded that: (1) there is ongoing activation of the testis at wk 21, (2) the production and secretion of testosterone were highly fluctuating, (3) there is no correlation between pituitary bioCG with either serum or intratesticular testosterone, indicating partial independence of ITA production from pituitary CG, and (4) the marmoset monkey reaches the threshold of puberty at and around $43 \mathrm{wk}$ of age, attains all the qualitative parameters of spermatogenesis at and around wk 52, and matures further, reaching sexual maturity at $70 \mathrm{wk}$. This, in association with available concentrations of testosterone might be the reason why the marmoset initiated copulation between these two age groups (Abbott \& Hearn 1978). Our observations about endocrine and reproductive changes around puberty provide substantial baseline values in the marmoset monkey (C. jacchus), which should be helpful in designing future studies in this model. The knowledge that testicular maturation occurs in the presence of highly fluctuating testosterone levels and barely detectable serum CG concentrations should be considered in studies on testicular grafting in this species.

\section{Acknowledgements}

Susan Nieschlag deserves special thanks for language editing of the paper. Sandhowe-Klaverkamp, Salzig, Köckemann, and Kersebom are gratefully acknowledged for technical assistance in hormone measurement and histology. Martin Heuermann and Günter Stelke, the animal caretakers of the Institute, deserve special acknowledgement for their cooperation during the entire period of study. The authors declare that there is no conflict of interest that would prejudice the impartiality of this scientific work. 


\section{References}

Abbott DH \& Hearn JP 1978 Physical, hormonal and behavioural aspects of sexual development in the marmoset monkey, Callithrix jacchus. Journal of Reproduction and Fertility 53 155-166.

Chandolia RK, Weinbauer GF, Simoni M, Behre HM \& Nieschlag E 1991 Comparative effects of chronic administration of the nonsteroidal antiandrogens flutamide and Casodex on the reproductive system of the adult male rat. Acta Endocrinologica (Copenh) 125 547-555.

de Souza P, Rune GM, Heger W \& Merker HJ 1988 Spermatogenesis from birth to sexual maturity in the marmoset testis. In Non-human Primates - Developmental Biology and Toxicology, pp 511-528. Eds D Neubert, H-J Merker \& C Hendricks. Berlin: UeberreuterWissenschafts Verlag.

Dixson AF 1986 Plasma testosterone concentrations during postnatal development in the male common marmoset. Folia Primatologica (Basel) 47 166-170.

Gromoll J, Wistuba J, Terwort N, Godmann M, Müller T \& Simoni M 2003 A new subclass of the luteinizing hormone/chorionic gonadotropin receptor lacking exon 10 messenger RNA in the New World monkey (Platyrrhini) lineage. Biology of Reproduction 69 75-80.

Hodges JK 1978 Effects of gonadectomy and oestradiol treatment on plasma luteinizing hormone concentrations in the marmoset monkey, Callithrix jacchus. Journal of Endocrinology 76 271-281.

Hodges JK \& Hearn JP 1977 Effects of immunisation against luteinising hormone releasing hormone on reproduction of the marmoset monkey Callithrix jacchus. Nature 265 746-748.

Hodges JK, Eastman SA \& Jenkins N 1983 Sex steroids and their relationship to binding proteins in the serum of the marmoset monkey (Callithrix jacchus). Journal of Endocrinology 96 443-450.

Jackson MR \& Edmunds JG 1984 Morphological assessment of testicular maturity in marmosets (Callithrix jacchus). Laboratory Animals 18 173-178.

Kelnar CJ, McKinnell C, Walker M, Morris KD, Wallace WH, Saunders PT, Fraser HM \& Sharpe RM 2002 Testicular changes during infantile 'quiescence' in the marmoset and their gonadotrophin dependence: a model for investigating susceptibility of the prepubertal human testis to cancer therapy?. Human Reproduction 17 1367-1378.

Kholkute SD, Aitken RJ \& Lunn SF 1983 Plasma testosterone response to hCG stimulation in the male marmoset monkey (Callithrix jacchus jacchus). Journal of Reproduction and Fertility 67 457-463.

Li LH, Donald JM \& Golub MS 2005 Review on testicular development, structure, function, and regulation in common marmoset. Birth Defects Research Part B: Developmental and Reproductive Toxicology 74 450-469.

Luetjens CM, Weinbauer GF \& Wistuba J 2005 Primate spermatogenesis: new insights into comparative testicular organisation, spermatogenic efficiency and endocrine control. Biological Reviews of the Cambridge Philosophical Society $80475-488$.

Luetjens CM, Wesselmann R \& Kuhlmann M 2006 GnRH-antagonist mediated down-regulation of the estrous cycle in marmosets. Journal of Medical Primatology [in press].

Lunn SF, Dixson AF, Sandow J \& Fraser HM 1990 Pituitary-testicular function is suppressed by an LHRH antagonist but not by an LHRH agonist in the marmoset monkey. Journal of Endocrinology 125 233-239.

Lunn SF, Recio R, Morris K \& Fraser HM 1994 Blockade of the neonatal rise in testosterone by a gonadotrophin-releasing hormone antagonist: effects on timing of puberty and sexual behaviour in the male marmoset monkey. Journal of Endocrinology 141 439-447.
Lunn SF, Cowen GM \& Fraser HM 1997 Blockade of the neonatal increase in testosterone by a $\mathrm{GnRH}$ antagonist: the free androgen index, reproductive capacity and postmortem findings in the male marmoset monkey. Journal of Endocrinology 154 125-131.

McGuinness MP \& Orth JM 1992 Gonocytes of male rats resume migratory activity postnatally. European Journal of Cell Biology $\mathbf{5 9}$ 196-210.

Millar MR, Sharpe RM, Weinbauer GF, Fraser HM \& Saunders PT 2000 Marmoset spermatogenesis: organizational similarities to the human. International Journal of Andrology 23 266-277.

Müller T, Simoni M, Pekel E, Luetjens CM, Chandolia R, Amato F, Norman RJ \& Gromoll J 2004 Chorionic gonadotrophin beta subunit mRNA but not luteinising hormone beta subunit mRNA is expressed in the pituitary of the common marmoset (Callithrix jacchus). Journal of Molecular Endocrinology 32 115-128.

Pugeat M, Rocle B, Chrousos GP, Dunn JF, Lipsett MB \& Nisula BC 1984 Plasma testosterone transport in primates. Journal of Steroid Biochemistry 20 473-478.

Rune GM, de Souza P \& Merker HJ 1991 Ultrastructural and histochemical characterization of marmoset (Callithrix jacchus) Leydig cells during postnatal development. Anatomica Embryologica (Berl) 183 179-191.

Sharpe RM, Walker M, Millar MR, Atanassova N, Morris K, McKinnell C, Saunders PT \& Fraser HM 2000 Effect of neonatal gonadotropin-releasing hormone antagonist administration on sertoli cell number and testicular development in the marmoset: comparison with the rat. Biology of Reproduction 62 1685-1693.

Sharpe RM, Fraser HM, Brougham MF, McKinnell C, Morris KD, Kelnar CJ, Wallace WH \& Walker M 2003 Role of the neonatal period of pituitary-testicular activity in germ cell proliferation and differentiation in the primate testis. Human Reproduction 18 2110-2117.

Weinbauer GF, Aslam H, Krishnamurthy H, Brinkworth $\mathrm{MH}$, Einspanier A \& Hodges JK 2001 Quantitative analysis of spermatogenesis and apoptosis in the common marmoset (Callithrix jacchus) reveals high rates of spermatogonial turnover and high spermatogenic efficiency. Biology of Reproduction 64 120-126.

Wickings EJ, Qazi MH \& Nieschlag E 1979 Determination ob biologically active LH in the serum of male rheusus monkeys (Macaca mulatta). Journal of Reproduction and Fertility 57 497-504.

Wistuba J, Schrod A, Greve B, Hodges JK, Aslam H, Weinbauer GF \& Luetjens CM 2003 Organization of seminiferous epithelium in primates: relationship to spermatogenic efficiency, phylogeny, and mating system. Biology of Reproduction 69 582-591.

Wistuba J, Mundry M, Luetjens CM \& Schlatt S 2004 Cografting of hamster (Phodopus sungorus) and marmoset (Callithrix jacchus) testicular tissues into nude mice does not overcome blockade of early spermatogenic differentiation in primate grafts. Biology of Reproduction 71 2087-2091.

Wistuba J, Luetjens CM, Wesselmann R, Nieschlag E, Simoni M \& Schlatt S 2006 Meiosis in autologous ectopic transplants of immature testicular tissue grafted to Callithrix jacchus. Biology of Reproduction 74 706-713.

Zitzmann M, Depenbusch M, Gromoll J \& Nieschlag E 2003 Prostate volume and growth in testosterone-substituted hypogonadal men are dependent on the CAG repeat polymorphism of the androgen receptor gene: a longitudinal pharmacogenetic study. Journal of Clinical Endocrinology and Metabolism 88 2049-2054.

Received 16 March 2006

First decision 27 April 2006

Revised manuscript received 19 May 2006

Accepted 26 May 2006 